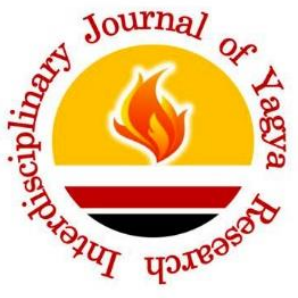

INTERDISCIPLINARY JOURNAL OF YAGYA RESEARCH

Peer Reviewed Research Journal

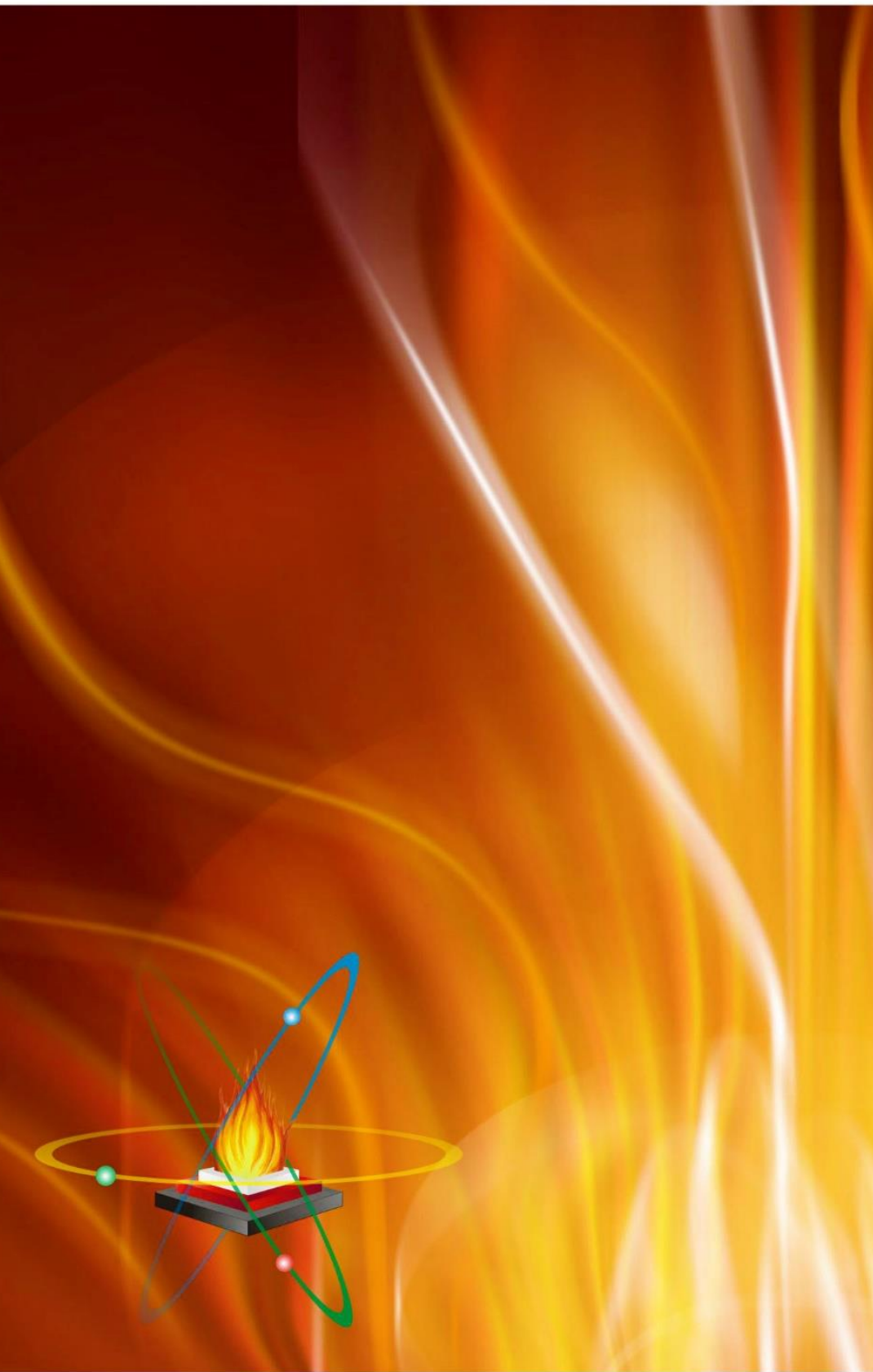

VOLUME 1 ISSUE 2 


\title{
Yagya Therapy for Epileptic Seizures: A Case Study
}

\author{
Lalima Batham $^{1 *}$, Lokesh Choudhary ${ }^{2}$, Alka Mishra $^{3}$, Vandana Shrivastava ${ }^{4}$
}

${ }^{1}$ Office Assistant, Panchakarma Center, Department of Ayurveda and Holistic Health, Dev Sanskriti Vishwavidyalaya, Haridwar

${ }^{2}$ Research Scholar, Department of Yog and Ayurveda, Sanchi University of Buddhist-Indic Studies, Madhya Pradesh

${ }^{3}$ Assistant Professor, Department of Ayurveda and Holistic Health, Dev Sanskriti Vishwavidyalaya, Haridwar

${ }^{4}$ Associate Professor, Department of Ayurveda and Holistic Health, Dev Sanskriti Vishwavidyalaya, Haridwar

*Corresponding author: Lalima Batham. Email: lalima.batham@dsvv.ac.in

\begin{abstract}
Epileptic seizure is a neurological condition in which brief to long episodes of vigorous shaking, convulsions, blackouts, fainting, unresponsiveness, jerks, etc. occur in the patients. Current treatment approaches are anti-seizure medicines, which patients are bound to take throughout life. These medications are mostly not able to reverse or eradicate the condition. Vedic literature recommends Yagya as a therapy for mental conditions similar to mania, seizure, etc. YagyaTherapy provides pulmonary inhalation of medicinalsmoke of multiple herbs (generated through oblation in fire along with chanting of Vedic hymns), which have the potential for seizure treatment. A case study is being reported wherein Yagya-Therapy was
\end{abstract}

prescribed to an epileptic seizure patient. Before the start of Yagya-Therapy, the patient (Male/65 years) had been suffering from epileptic seizures ( 8-10 episodes annually) since $\sim 3$ years (pre-observation). Subsequently, the patient has been doing YagyaTherapy since past $\sim 3.5$ years, wherein only $2-3$ episodes occurred during the first year, that too during sleep only, and after that no seizures have been experienced. All this time, the patient continued to take the allopathic medication that he was taking earlier. Thus, Yagya-Therapy can be an effective treatment option for epileptic seizure patients.

Keywords. Epilepsy, Epileptic Seizures, Yagya Therapy, Medicinal Smoke, Multiple Herbs 


\section{Introduction}

Epilepsy is a neuropsychiatric disorder with widespread presence. In India, about 12 million people suffer from epilepsy of the 70 million patients with epilepsy in the world (1). It is one of the most chronic neurological brain disorder in Europe $(2,3)$. According to the World Health Organization and the World Bank, the costs of epilepsy constitute $0.5 \%$ of all diseases (4).

In modern allopathic medicine, the current treatment approach includes anti-seizure medicines for epileptic patients, which the patients are bound to take long time and these medications are mostly not able to reverse or eradicate the condition completely (5). Thus, there is a definite need to look for other therapeutic approaches, which can effectively manage epileptic seizures.

Yagya Therapy or Yagyopathy is an ancient Indian method of herbal inhalation therapy that allows for the pulmonary administration of herbs. In this process, coarse powder of multiple herbs is converted in medicinal smoke by offering these in the fire during the traditional Vedic ritual called Yagya $(6,7)$. Patient is asked to inhale medicinal smoke, which contains phyto-constituents that provide therapeutic advantage $(8,9)$. The method of medicinal smoke inhalation is not a new concept, rather, it prevailed in many traditional and cultural practices for pulmonary and neuronal diseases (10). Yajurveda espoused performing of Hawan every day, morning and evening, to attain spiritual refinement, mental peace, purification of the mind (11) and environment (12, 13). From time immemorial, human beings have used smoke of medicinal plants for curing diseases. Ayurveda also recommended nasal route as a preferred mode of administration of drugs for epilepsy (14).

Yagya Therapy, as a tool for medicinal smoke inhalation, has shown therapeutic advantage in tuberculosis $(15,16)$, mental health (17), HIV infection (18), and cancer (19) patients. Furthermore, several medicinal plants like Jatamansi (Nardostachys jatamansi) (reviewed in 20), Nagarmotha (Cyperus rotundus) (reviewed in 20), etc. have shown therapeutic advantage in epileptic seizures. Thus, administration of Yagya Therapy, using the appropriate medicinal herbs, can be an effective therapeutic approach for the management of epileptic seizures. The present paper describes a case study wherein the effect of Yagya Therapy, using an appropriate herbal formulation, on a patient, who had been suffering from epileptic seizures has been explored.

\section{Methods}

In the present paper, the effect of Yagya Therapy was explored on a patient, who had been suffering from epileptic seizures.

\section{History of the patient and course of treatment}

A 65 year old male patient was having adult onset epilepsy, which was first detected in July 2012 (Figure 1). Subsequently, the patient was put on allopathic medication, but he had poor control with anti-epileptic drugs (AED), i.e. during the first 3 years of taking allopathic medication, the patient continued to experience about 8 seizure episodes annually (Figure 1). The patient also had a history of memory impairment, hypertension and type 2 diabetes mellitus since 2012 (as per the doctor's diagnosis).

Looking at the beneficial effect of various medicinal herbs in the management of Epileptic Seizures, and the effectiveness of Yagya Therapy in administering herbal formulations through the nasal route in the form of medicinal smoke, the patient was advised to take Yagya Therapy as an add-on therapy. Before starting Yagya Therapy, the patient had been taking the aforesaid allopathic medication since 2 years and 9 months. Subsequently, the patient continued to take the allopathic medication, and started taking Yagya Therapy as an add-on therapy; at the time of the final evaluation reported in the present paper, it had been 3 years and 5 months since the patient started taking Yagya Therapy. It is noteworthy that 2 months before the final evaluation reported in the present paper, the patient tapered his intake of allopathic medication as per the advice of the modern medicine doctors (Figure $1)$.

Procedure of Yagya and herbal preparation intake Patient was advised by the Department of Ayurveda and Holistic Health (DAHH), Dev Sanskriti 
Vishwavidyalaya, Haridwar to follow the standard protocol of Yagya, at home. The detailed protocol has been described in earlier publications (ref, ref). Briefly, the procedure included doing Shatkarma (Pavitrikaran, Achaman, Shikhavandan, Nasya) (i.e. spiritual practices for purification), Prithvi Pujan, Chandandharan, Guru-avahan, 24 oblations of the herbal mixture (hawan samagri) in the fire along with the chanting of Gayatri Mantra, followed by Pranayama for 10 minutes $(21,22)$. Patient was advised to use copper pot (in which the fire is generated), mango sticks (for generating the fire), ghee (clarified butter made from indigenous cow's milk), and herbal preparation (hawan samagri) prescribed by Department of Ayurveda and Holistic Health. The patient performed Yagya daily in the morning, in a small Yagya-room of a temple in his locality. Subsequently, he performed pranayama in the same room for another 15 minutes.

Herbal mixture (hawan samagri) preparation

Since past several years, the Department of Ayurveda and Holistic Health (DAHH) (earlier Center for Ayurveda Studies, and before that Center of Holistic Health Management), Dev Sanskriti Vishwavidyalaya, Haridwar, Uttarakhnad has been prescribing Yagya Therapy (Yagyopathy), wherein different herbal preparations of Ayurvedic plant medicines (hawan samagri) have been made in-house for various diseases.

With regards to the present study, DAHH prescribed a hawan samagri for Epilepsy treatment, which consists of about 23 herbs (21). No metal was used in the herbal preparation. All ingredients were well identified by taxonomist (23), were non-toxic, and could be useful in the treatment of Epilepsy, and the associated disorders (20-21,24-25). Some of the herbs whose effectiveness in the management of epileptic seizure, and associated disorders, has been described in the open literature include: Jatamansi (Nardostachys jatamansi) (20), Nagarmotha (Cyperus rotundus) (20), Ashwagandha (Withania somnifera) (24), Mustard seeds (Brassica nigra) (26), Punarnava (Boerhavia diffusa) (21), etc. Along with the hawan samagri for Epilepsy, patient was also prescribed a common purpose immunityboosting hawan samagri; hawan samagri for Epilepsy and common purpose hawan samagri had to be mixed in $3: 1$ ratio, and then the oblations had to be made in the fire with this mixture.

\section{Patient Evaluation}

Patient's prior consent was taken to use his medical records data for research publication, without revealing his identity. Patient provided copies of his past medical reports, and gave verbal testimonial of his experience during the course of the treatment.

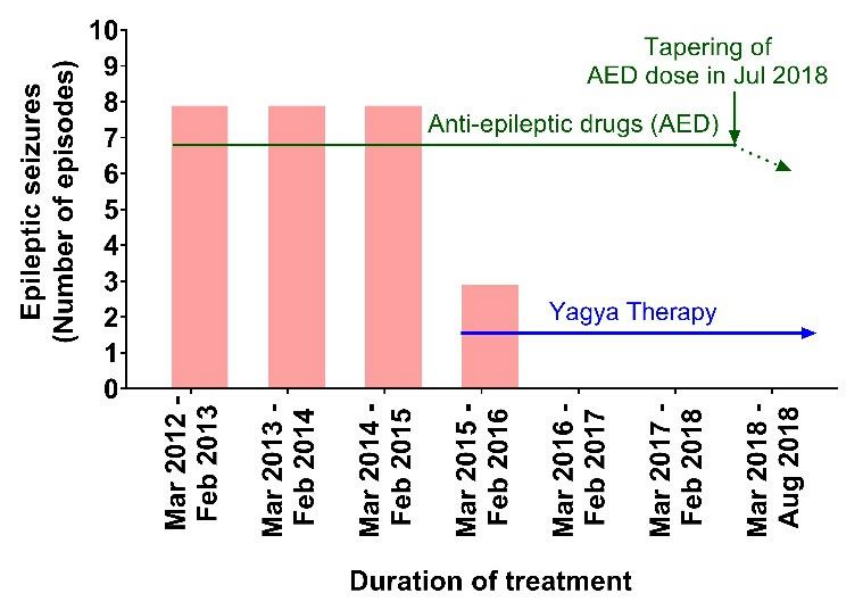

Figure 1. Annual number of episodes of epileptic seizures patient experienced throughout duration of allopathic treatment and after start of Yagya Therapy as add on. Y-axis is number of epileptic episodes. $\mathrm{X}$-axis is duration of treatments. Horizontal green-arrow indicates course of antiepileptic drugs. Vertical green-row indicates that time when tapering of AED drug started. Horizontal blue-arrow indicates start and continuity of the Yagya Therapy. Episodes after start of Yagya Therapy in March 2015 were only during sleep.

\section{Results}

Patient provided copies of medical reports that confirmed the diagnosis of Adult Onset Epilepsy, and gave an account of the allopathic medication prescribed to him thereafter. The reports also indicated that the patient had poor control by anti-epileptic drugs, and hence was advised to take expert opinion as well.

In his verbal testimonial, the patient described his experience during the course of the treatment. The patient informed that after the diagnosis of the disease in mid-2012, he continued with the allopathic medication for about 3 years, during which, almost 
after every one and a half month he experienced one episode of epileptic seizure, i.e. about 8 seizure episodes annually (Figure 1). Subsequently, he was advised to take Yagya Therapy during the first half of 2015 as an add-on therapy along with the allopathic medication. He started Yagya Therapy immediately and has continued it till date.

After the start of Yagya-Therapy, during the entire first year, i.e. 2015, the patient experienced only about 2 to 3 seizure episodes (Figure 1) during sleep, as reported by his wife, and none during wakeful condition. After that, he has not experienced even a single seizure episode till date. All this time, the patient continued to take the allopathic medication that he had been taking earlier. Looking at the improvement in his condition after 2015, during a recent follow-up visit to his allopathic medicine doctor, he was advised to taper (reduce) the dose of allopathic medication (Sodium valproate) from $400 \mathrm{mg}$ to $200 \mathrm{mg}$, once a day.

\section{Discussion}

The present study indicates the potential of Yagya Therapy as a supportive or adjunct therapy for the treatment of epileptic seizures.

Venkataraghavan et al. (27) have mentioned, that as per Ayurvedic texts, Apasmara is a disease that has similar symptoms as those found in epilepsy. The word Apasmara is made up of two words - Smara means memory, which includes memory, intelligence and consciousness; and, Apa means loss - thus, loss of consciousness is one of the important signs in Apasmara (27). As per Ayurvedic texts, epileptic seizures have been classified into four major groups caused by the derangement of the three humours (doshas), i.e. Vata, Pitta, and Kapha, and the fourth variety caused by their combined effects (Sannipata) $(14,28)$, and hence the medicinal herbs that balance the respective doshas, are used in the Ayurvedic treatment of epileptic seizures.

In Yagya Therapy, the herbal preparation contained herbs, which were chosen based on careful review of Ayurvedic pharmacology, modern pharmacology, and scriptural indications. Their aromatic volatile oil helps in the treatment of epileptic seizures (20-21, 24-26). For example, Bansal et al. have studied the applicability of hawan for the treatment of epilepsy, and have described the utility and probable mode of action of various medicinal herbs, like Jatamansi, Nagarmotha, etc. that have known anticonvulsant activity (20).

One of the important aspect of Yagya Therapy for getting improved pathological condition is the pulmonary inhalation of medicinal-smoke of the prescribed herbs (15-19). As previously mentioned (8), pulmonary inhalation is an effective route to administer herbs, for various diseases, through the nasal route. Volatile phytochemicals impart the therapeutic advantage, just like in the case of aroma therapy.

Ancient Indian scriptures including Ayurvedic texts also prescribe specific mantras and different types of ghee for the treatment of epilepsy; use of mantras and ghee is an integral part of Yagya Therapy (14). The utilization of ghee in Yagya is also meant to give strength to patient, who otherwise cannot digest fat in diseased condition (29). Furthermore, according to modern research findings, lipid nanoparticles are shown to enhance drug delivery (30) through the nasal route (8).

In the present study, the patient took Yagya Therapy along with modern allopathic medication, and reported notable benefits in his condition, indicating that Yagya Therapy is a safe and compatible therapy, as adjunct therapy, in the treatment of epileptic seizures. It is noteworthy that the present study was done in OPD (Out-Patient Department) setting, wherein the patient was prescribed the therapy, and was required to do Yagya at his home. Such a setting has obvious limitations with regards to following the prescribed procedure; however, the patient still reported notable benefit due to Yagya Therapy.

Thus, the present study shows encouraging result with regards to the effectiveness of Yagya Therapy in the treatment of epileptic seizures. Further studies are needed to establish the mechanism and role of Yagya Therapy in the treatment of epileptic seizures. 


\section{References}

1. Amudhan S, Gururaj G, Satishchandra P. Epilepsy in India I: Epidemiology and public health. Ann Indian Acad Neurol. 2015;18(3):263-77. Available from: http://www.ncbi.nlm.nih.gov/pubmed/26425001

2. Andlin-Sobocki P, Jonsson B, Wittchen H-U, Olesen J. Cost of disorders of the brain in Europe. Eur $\mathrm{J}$ Neurol. 2005;12(s1):1-27. Available from: http://www.ncbi.nlm.nih.gov/pubmed/15877774

3. Ivanova JI, Birnbaum HG, Kidolezi Y, Qiu Y, Mallett D, Caleo S. Direct and indirect costs associated with epileptic partial onset seizures among the privately insured in the United States. Epilepsia. 2010;51(5):838-44. Available from: http://www.ncbi.nlm.nih.gov/pubmed/20002150

4. Leonardi M, Ustun TB. The global burden of epilepsy. Epilepsia. 2002;43 Suppl 6:21-5. Available from: http://www.ncbi.nlm.nih.gov/pubmed/12190974

5. Hixson JD. Stopping antiepileptic drugs: when and why? Curr Treat Options Neurol. 2010;12(5):434-42. Available

from:

http://www.ncbi.nlm.nih.gov/pubmed/20730110

6. Brahmavarchas, editor. Yagyachikitsa-yagyopathy: ek samagra evam divya chikitsa paddhati (Hindi). In: Yagya Chikitsa. Shri Vedmata Gayatri Trust, Shantikunj, Haridwar (Uttarakhand), 249411, India; 2010:15-35

7. Pandya P. Applied Science of Yagya for Health \& Environment. Shri Vedmata Gayatri Trust, Shantikunj, Haridwar (Uttarakhand), 249411, India; 2009:1-117. Available from: www.awgp.org

8. Joshi RR, Raghuvanshi M, Pandya P. Yagyopathy versus oral and iv drug administration: evaluation for pulmonary tuberculosis using compartment modeling. J Biol Syst. 2006;14(03):463-89. Available from: http://www.worldscientific.com/doi/abs/10.1142/S0218339 006001891

9. Patel V, Mishra A, Shrivastav V. Pulmonary inhalation of medicinal smokes- an aspect of yagya therapy: an effective therapeutic application and efficient drug delivery model of multiple herbs. In: National Medicinal Plants Board (Ministry of AYUSH, Govt Of India) sponsored National conference on Recent Advances in Ayurvedic Herbal Medicine -Dehradun. 2017:16th Sept
10. Mohagheghzadeh A, Faridi P, Shams-Ardakani M, Ghasemi Y. Medicinal smokes. J Ethnopharmacol. 2006 Nov;108(2):161-84

11. Verma S, Mishra A, Shrivastava V. Yagya Therapy in Vedic and Ayurvedic Literature: A Preliminary exploration. Interdiscip J Yagya Res. 2018;1(1):15-20.

12. Tewary R, Mishra JK. Hawan-An effective method to reduce fungal load at small work places. Aerobiologia (Bologna). 1997;13(2):135-8. Available from: http://link.springer.com/10.1007/BF02694430

13. Saxena M, Kumar B, Matharu S. Impact of Yagya on Particulate Matters. Interdiscip J Yagya Res. 2018;1(1):01-8

14. Jain S, Tandon PN. Ayurvedic medicine and Indian literature on epilepsy. Neurol Asia. 2004;9(Supplement 1):57-8. Available from: http://www.neurologyasia.org/articles/20043_057.pdf

15. Raghuvanshi M, Pandya P, Joshi RR. Yagyopathic Herbal Treatment of Pulmonary Tuberculosis Symptoms: A Clinical Trial. Altern Complement Ther. 2004;10(2):101-5. Available from: http://www.liebertonline.com/doi/abs/10.1089/1076280047 73933352

16. Raghuvanshi M, Pandya P, Joshi RR. In-vitro Testing Of An Ethnobotanical Inhalation Therapy Against Pulmonary Tuberculosis. Phytotherapie. 2009;7(5):243-9

17. Sharma S. Yagya Chikitsa Dwara Manasik Swasthya Par Padane Vale Prabhav Ka Adhyayan (Hindi) (Dissertation). Dev Sanskriti Vishwavidyalaya, Shantikunj, Haridwar, Uttarakhand, India; 2009

18. Sharma P, Khokhar CP, Manchanda SC, Sharma N. Yagya Therapy for Managing Inferiority \& Insecurity feeling of HIV + / AIDS Patients. Dev Sanskriti Interdiscip Int J. 2012;01:70-7

19. Mishra A, Batham L, Shrivastava V. Yagya Therapy as supportive care in cancer patients improved quality of life: Case studies. Interdiscip J Yagya Res. 2018;1(1):26-33

20. Bansal P, Kaur R, Gupta V, Kumar S, Kaur R. Is There Any Scientific Basis of in Epilepsy-Prevention/Cure? J Epilepsy Res. 2015;5(2):33-45. Available from: 
http://www.j-

epilepsy.org/journal/view.php?doi=10.14581/jer.15009

21. Brahmavarchas, editor. Yagya Chikitsa. 1st ed. Shri Vedmata Gayatri Trust, Shantikunj, Haridwar (Uttarakhand), 249411, India; 2010;1-368

22. Vedmurti Taponishtha Pt. Shriram Sharma Acharya. Sankshipt Gayatri hawan vidhi (Hindi). Revision. Yug nirman yojana vistar trust, Gayatri Tapobhumi, Mathura; 2012:1-49

23. Sharma P. Dravyaguna Vijnana - Volume II (Hindi). Chaukhambha Bharati Academy, Varanasi, Uttar Pradesh, India; 2001

24. Liu W, Ge T, Pan Z, Leng Y, Lv J, Li B. The effects of herbal medicine on epilepsy. Oncotarget. 2017;8(29):4838597. Available from: http://www.ncbi.nlm.nih.gov/pubmed/28423368

25. Kiasalari Z, Khalili M, Roghani M, Sadeghian A. Antiepileptic and Antioxidant Effect of Brassica nigra on Pentylenetetrazol-Induced Kindling in Mice. Iran J Pharm Res IJPR. 2012;11(4):1209-17. Available from: http://www.ncbi.nlm.nih.gov/pubmed/24250555
26. Kaur M, Goel RK. Anti-Convulsant Activity of Boerhaavia diffusa: Plausible Role of Calcium Channel Antagonism. Evid Based Complement Alternat Med. 2011;9:310420. Available from: http://www.ncbi.nlm.nih.gov/pubmed/19948752

27. Venkataraghavan S, Rajagopalan V, Srinivasan K. Study of doshic involvement in apasmara (epilepsy) and its utility. Anc Sci Life. 1987;6(3):138-47. Available from: http://www.ncbi.nlm.nih.gov/pubmed/22557563

28. Tripathi M, Maheshwari M, Jain S, Srivastava $P$. Ayurvedic medicine and epilepsy. Neurological Journal of Southeast Asia. 2000;5:1-4

29. Brahmavarchas, editor. Yagya se rog-nivaran evam balsamvarddhan ke do labh. In: Yagya- ek samagra upcharprakriya (Pt Shriram Sharma Acharya Vangmay No 25). Akhand Jyoti Sansthan, Mathura-281003; 1994:1-12.6. Available from: www.literature.awgp.org

30. Pandya NT, Jani P, Vanza J, Tandel H. Solid lipid nanoparticles as an efficient drug delivery system of olmesartan medoxomil for the treatment of hypertension. Colloids Surfaces B Biointerfaces. 2018;165:37-44. Available from: 